American Journal of Biochemistry and Biotechnology 3 (1): 16-23, 2007

ISSN 1553-3468

(C) 2007 Science Publications

\title{
Attenuated Superoxide Dismutase Induction in Retinal Cells in Response to Intermittent High Versus Continuous High Glucose
}

\author{
${ }^{1}$ Michael A. Ihnat, ${ }^{2}$ Ronald C. Kaltreider' ${ }^{1}$ Jessica E. Thorpe, Dixy E. Green, ${ }^{1}$ Chandrashekhar D. Kamat, \\ ${ }^{2}$ Melissa Leeper, ${ }^{2}$ Amanda C. Shanner, ${ }^{1}$ Linda A. Warnke, ${ }^{3}$ Ludovica Piconi and ${ }^{4}$ Antonio Ceriello \\ ${ }^{1}$ Department of Cell Biology, University of Oklahoma Health Sciences Center, Oklahoma City, OK \\ ${ }^{2}$ Department of Biology, York College, York, PA \\ ${ }^{3}$ Morpurgo-Hofman Research Laboratory on Aging, Udine, Italy \\ ${ }^{4}$ Warwick Medical School, Coventry, U.K.
}

\begin{abstract}
High glucose, particularly in oscillating conditions, produces an increase in oxidative stress and has been shown to result in an increase in diabetic complications, retinopathy in particular. The hypothesis of this work was that chronic exposure to intermittent high glucose results in an attenuated induction of an antioxidant response as compared to continuous high glucose exposure in isolated retinal cells In this work, human retinal pericytes and ARPE- 19 cells were exposed to $5 \mathrm{mM}$ or $30 \mathrm{mM}$ continuous high glucose or to $5 \mathrm{mM}$ oscillating daily with $30 \mathrm{mM}$ glucose for 14 days. Levels of antioxidant proteins and activity and levels of reactive species protein adducts were measured. We demonstrate that the induction of total cellular superoxide dismutase (SOD) activity in isolated retinal pericytes and ARPE-19 cells is significantly attenuated in response to oscillating glucose as compared to continuous high glucose. We also show that a marker of nitrosative stress, 3-nitrotyrosine and a general marker of oxidized proteins, OxyBlot ${ }^{\mathrm{TM}}$, were significantly increased in both cell types exposed to intermittent high glucose as compared to continuous high glucose. Finally, we show that levels of nitrated MnSOD were increased in response to intermittent high versus continuous high glucose and that the addition of a reactive nitrogen species scavenger to oscillating glucose resulted in significantly increased levels of SOD activity. In conclusion, our results demonstrate for the first time a link between intermittent high glucose and a decreased induction of an antioxidant response of SOD.
\end{abstract}

Key words: Intermittent high glucose, antioxidant, superoxide dismutase, retinal pericytes, retinal pigment epithelium, nitration

\section{INTRODUCTION}

In addition to continuous hyperglycemia, postprandial oscillations in glucose levels, like those experienced in the daily life of diabetic patients, have recently been suggested as an independent risk factor for both cardiovascular and microvascular diabetic complications $^{[1,2]}$, in particular retinopathy ${ }^{[3]}$. This concept is consistent with the findings that intermittent high glucose has been shown to lead to increased damage to the endothelial cells ${ }^{[4-7]}$, mesangial cells $^{[8]}$ and tubulointerstitial cells ${ }^{[9]}$ in culture.

Brownlee et al. ${ }^{[10-12]}$ have recently proposed a "unifying mechanism" by which all the pathways involved in the pathogenesis of diabetic complications are linked through a hyperglycemia-driven intracellular excess of reactive oxygen species (ROS), superoxide anion in particular. Therefore, it is not surprising that an increase in antioxidant defense is a common response to ROS overproduction from target cells, particularly in hyperglycemic conditions ${ }^{[11,12]}$. We have recently shown that oscillations in glucose levels also result in increased levels of markers of reactive species and vascular stress both in endothelial cells in culture ${ }^{[5-7]}$ and in patients ${ }^{[13,14]}$ therefore a possible explanation for the increased damage in response to intermittent high as compared to continuous high glucose would be that the cells of the vasculature and target organs are unable to mount as extensive an antioxidant response.

Diabetic retinopathy is a common complication of diabetes and the leading cause of blindness in the western world $^{[15]}$. In the first stages of diabetic
Corresponding Author:

Antonio Ceriello, Warwick Medical School, Clinical Science Research Institute, Clinical Science Building, University Hospital - Walsgrave Campus, Clifford Bridge Road, Coventry CV2 2DX, U.K., Tel: +440247696 8582, Fax: +4402476968653 
retinopathy there are changes in the pericytes surrounding the retinal vasculature leading ultimately to their apoptotic death ${ }^{[16-18]}$. The retinal pigment epithelium (RPE) layer, helping to form the bloodretinal barrier, is not known to die but does undergo considerable morphological and biochemical changes in response to high glucose ${ }^{[19-21]}$. The RPE has also been shown to protect the eye against ROS-induced damage by intense light ${ }^{[22]}$, perhaps with an enhanced antioxidant response.

Because, as recently reviewed, in the diabetic retina in response to hyperglycemia there are increases in oxidative stress due to excess mitochondrial reactive species production, an increase in adducted (nitrosylated) proteins and an impairment of antioxidant defense enzymes ${ }^{[23]}$, the hypothesis of the research described herein was that chronic exposure to intermittent high glucose results in an attenuated induction of an antioxidant response as compared to continuous high glucose exposure in isolated retinal cells. We now report for the first time that intermittent high glucose results an attenuated induction of SOD activity and increased levels of nitrated SOD protein as compared to continuous high glucose.

\section{MATERIALS AND METHODS}

Chemicals: All chemicals were from Sigma Chemical (St. Louis, MO) and all tissue culture reagents were from Invitrogen (Grand Island, NY) unless otherwise noted.

Cell culture and creation of transformed human retinal pericytes: Because of inconsistent growth conditions (varied doubling times, varied passage numbers to senescence) of primary isolates of human retinal pericytes, an SV40 $\mathrm{T}$ antigen transformed variant of these cells was created. To accomplish this, a mammalian $\mathrm{T}$ antigen expression vector was created by ligating the SV T-antigen gene from pUCTag (American Type Culture Collection, Manassas, VA) into a mammalian expression vector (pCMVTNT; Promega Corporation, Madison, WI). Isolated human retinal pericytes (Clonetics/Biowhittaker, East Rutherford, NJ) were transfected at $60 \%$ confluence in a well of a 6 -well plate using $2 \mu \mathrm{g}$ SV40 $\mathrm{T}$ antigen expression vector from above and Fugene transfection reagent (Roche, Indianapolis, IN). Clones were then selected for accelerated growth (not shown). A single clone, termed Huperi-3, was used for the experiments in this work. The characteristics of this isolate were as follows: a similar morphology as the parental isolates, expression of SV40 large T antigen, desmin and $\alpha-$ smooth muscle actin by western blot (not shown), an average doubling time of $39.1 \mathrm{hr}$, cells were passaged 1:4 twice wkly and cells could be passaged up to 30 times without any apparent change in growth or morphology. These transformed pericytes or ARPE-19 retinal pigment epithelial cells (American Type Culture Collection (Manassas, VA) were exposed to $5 \mathrm{mM}$ (controlled to $30 \mathrm{mM}$ osmolarity with L-glucose) or 30 $\mathrm{mM}$ glucose in DMEM with 10\% Cosmic calf serum (HyClone, Logan, UT) for 14 days. For oscillating glucose experiments, the $5 \mathrm{mM}$ glucose was interchanged with $30 \mathrm{mM}$ on a daily basis ${ }^{[4-7,9]}$. To the last wk of oscillating glucose was added either $200 \mu \mathrm{M}$ $\alpha$-lipoic acid ${ }^{[24]}$, or $1 \mathrm{mM} \mathrm{N}$-acetylcysteine ${ }^{[25]}$, or $50 \mu \mathrm{M}$ 2-phenyl-4,4,5,5-tetramethylimidazoline-1-oxyl-3oxide (PTIO) ${ }^{[5]}$. None of these treatments were found to have a significant effect on cell growth as compared to oscillating glucose given alone. Primary isolates of human RPE were also examined but did not possess robust enough growth characteristics to yield enough material for these studies (not shown). All treatment groups received fresh media daily, ensuring that both the continuous high glucose and intermittent high glucose groups were given $30 \mathrm{mM}$ glucose the day before the experiments concluded.

SOD and MnSOD activity: A commercially available SOD kit (Cayman Chemical; Ann Arbor, MI) was used to assess SOD enzyme activity. Briefly, cellular lysates were made in a $20 \mathrm{mM}$ HEPES (pH7.2), $1 \mathrm{mM}$ EGTA, $210 \mathrm{mM}$ mannitol, $70 \mathrm{mM}$ sucrose buffer and frozen at $-80^{\circ} \mathrm{C}$. Samples were combined with a radical detector and reactions initiated by the addition of xanthine oxidase. After $20 \mathrm{~min}$ incubation at RT, the absorbance was determined at $450 \mathrm{~nm}$. $3 \mathrm{mM} \mathrm{KCN}$ was added to the mixture to inhibit extracellular SOD and $\mathrm{Cu}, \mathrm{Zn}$ SOD to measure specifically MnSOD activity. SOD activity was then calculated using a SOD standard curve. Purified bovine erythrocyte SOD isoforms was used as a positive control for SOD enzyme induction.

Glutathione peroxidase (GPX) activity: GPX activity was measured by a commercially available kit (Cayman Chemical; Ann Arbor, MI). Cell lysates were collected into a $50 \mathrm{mM}$ Tris ( $\mathrm{pH}$ 7.5), $5 \mathrm{mM}$ EDTA, $1 \mathrm{mM}$ DTT buffer. Samples were combined with a mixture of glutathione, glutathione reductase and NADPH. The reaction was initiated by the addition of cumene hydroperoxide and GPx activity was measured as a decrease in absorbance at $340 \mathrm{~nm} / \mathrm{min}$ over $7 \mathrm{~min}$. Purified bovine erythrocyte GPx was used as a positive control for enzyme induction. Basal (5 mM glucose) levels for GPX were $1481.0 \pm 1919 \mathrm{U} / \mathrm{mg}$ for pericytes and $173.9 \pm 51.5 \mathrm{U} / \mathrm{mg}$ for ARPE-19 cells. 
Catalase (CAT) activity: CAT activity was measured by a commercially available kit (Cayman Chemical; Ann Arbor, MI). In this assay, methanol in the presence of an optimal concentration of $\mathrm{H}_{2} \mathrm{O}_{2}$ is reacted with cell lysates. The formaldehyde produced is measured spectrophotometrically with 4-amino-3-hydrazino-5mercapto-1,2,4-triazole (Purpald) as the chromogen. For the procedure, cell lysates were collected into a 50 $\mathrm{mM}$ potassium phosphate $(\mathrm{pH}$ 7.0), $1 \mathrm{mM}$ EDTA buffer. Samples were combined with methanol and assay buffer and reactions initiated with addition of hydrogen peroxide. After 20 min incubation at RT, reactions were terminated by addition of potassium hydroxide and shaken for $10 \mathrm{~min}$. Potassium periodate was then added to each well ( $5 \mathrm{~min}$ incubation) and the absorbance determined at $540 \mathrm{~nm}$. CAT activity was determined using a formaldehyde standard curve and purified bovine liver CAT was used as a positive control for this reaction. Basal ( $5 \mathrm{mM}$ glucose) levels for CAT were $11.5 \pm 2.7 \mathrm{U} / \mathrm{mg}$ for pericytes and 180.6 $\pm 36.3 \mathrm{U} / \mathrm{mg}$ for ARPE-19 cells.

Cellular lysate preparation: Whole cell extracts were made using a mammalian cell lysis buffer (M-PER; Pierce Chemical) containing protease and phosphatase inhibitor cocktails (EMD Biosciences and Sigma Chemical, respectively). Protein concentrations were measured by a colorimetric assay (micro BCA; Pierce Chemical, Rockland, IL).

Immunoprecipitation and Western blot: Cell lysates $(75 \mu \mathrm{g})$ were immunoprecipitated using an antibody against MnSOD ( $2 \mu \mathrm{g} / 75 \mu \mathrm{g}$ of sample protein) (Abcam, Littleton, CO) and subjected to SDS-PAGE, transferred to nitrocellulose and immunoblotted for 3-NT (antirabbit, 1:200, Upstate Biotech, Lake Placid, NY) and immmunoblot against MnSOD (anti-mouse, 1:1000, BD Biosciences Pharmingen, San Jose, CA) used as a control for immunoprecipitation.

For the western blots, equal amounts of lysates (20$50 \mu \mathrm{g}$ ) from cells treated as above were separated by SDS-PAGE and transferred to $0.2 \mu \mathrm{m}$ nitrocellulose (Schleicher and Schuell, Keene, NH). Membranes were blocked $2 \mathrm{hr}$ at RT in StartingBlock (TBS) blocking buffer (Pierce Chemical, Rockland, IL). Membranes were washed in TBS with $0.1 \%$ tween-20 (TBST) and exposed to primary antibodies overnight at $4^{\circ} \mathrm{C}$ or $2 \mathrm{hr}$ at room temperature (RT) with rocking. Membranes were washed in TBST, secondary peroxidaseconjugated antibodies (Pierce Chemical, Rockland, IL) added at 1:2500 dilution for $1 \mathrm{hr}$ at RT and the membranes washed again in TBST. ECL reagent (SuperSignal Dura; Pierce Chemical, Rockland, IL) was added for 5 minutes and images captured using a CCD digital darkroom (UV Products, Upland, CA). Antibodies against $\mathrm{Cu}, \mathrm{Zn}$ SOD (Santa Cruz Biotechnology; 1:200 dilution), MnSOD (Abcam, Cambridge, MA; 1:500 dilution), GPX1 (Abcam, Cambridge, MA; 1:200 dilution), CAT (Abcam, Cambridge, MA; 1:400 dilution), 3-NT (Upstate Biotech, Lake Placid, NY; 1:750 dilution), $\beta$-actin (Abcam, Cambridge, MA; 1:2000) and DNP (OxyBlot ${ }^{\mathrm{TM}}$, Chemicon; 1:150 dilution) were used.

Statistics: Data were analyzed using one-way analysis of variance to compare the means of all the groups. The Neuman-Keuls multiple comparisons procedure was used to determine which pairs of means were different. Difference were considered significant at $P<0.05$.

\section{RESULTS}

Intermittent high glucose exposure and antioxidant enzymes in retinal cells: Human retinal pericytes and human retinal pigment epithelial (ARPE-19) cells were exposed to $5 \mathrm{mM}$ (normal), or $30 \mathrm{mM}$ (high continuous) or 5/30 mM daily oscillating glucose for 14 days, a scheme we have previously used for endothelial cells $\mathrm{s}^{[4-6]}$. The first enzymes measured were the SODs, which catalyze the formation of hydrogen peroxide from superoxide anion. As has been shown previously for endothelial and mesangial cells ${ }^{[11,12]}$, chronic exposure to continuous high glucose resulted in significantly increased levels of total SOD and MnSOD activity in both cell types (Fig. 1E-H). Intermittent high (oscillating) glucose, however, was not accompanied by a similar increase in total SOD and MnSOD activity (Fig. 1E-G). Further, levels of MnSOD and $\mathrm{Cu}, \mathrm{Zn}$ SOD protein (Fig. 1A-D) did not match corresponding activity (Fig. 1E-H) levels. GPx and CAT work in concert to catalyze the breakdown of hydrogen peroxide, produced by SOD, to water. In contrast to SOD, there was very little induction of GPx or CAT in response to either high continuous or intermittent high glucose alone in either retinal cell type (not shown). As with the SOD enzymes, the levels of GPx and CAT proteins did not correlate with their corresponding enzyme activity (not shown).

Intermittent high glucose results in increased 3-NT levels in retinal cells: 3-nitrotyrosine (3-NT) is a protein adduct generated by reactive nitrogen species (RNS) such as peroxynitrite $\left(\mathrm{ONOO}^{-}\right)$, formed by superoxide anion $\left(\mathrm{O}_{2} \bullet^{-}\right)$and nitric oxide $(\mathrm{NO} \bullet)$; and nitrogen dioxide radical $\left(\mathrm{NO}_{2}{ }^{\bullet}\right)$, formed from hydrogen peroxide $\left(\mathrm{H}_{2} \mathrm{O}_{2}\right)$ and nitrite $\left(\mathrm{NO}_{2}^{-}\right)^{[26]}$. 3-NT protein 
Am. J. Biochem. \& Biotech., 3 (1): 16-23, 2007

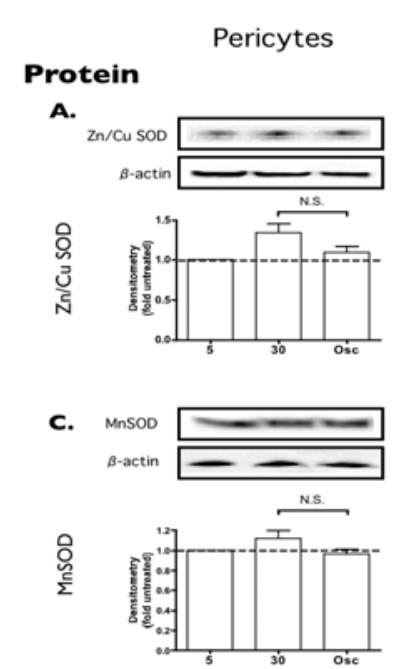

Activity

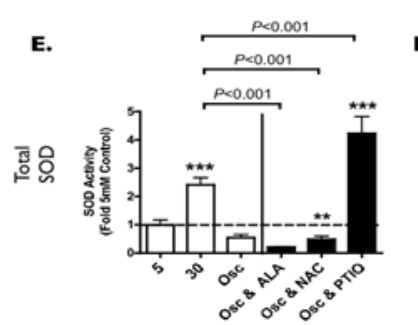

B.
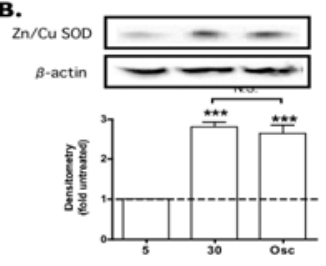

D. Mnsoo

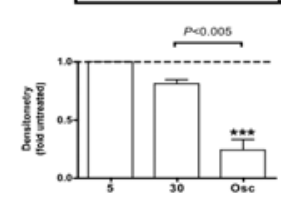

F.

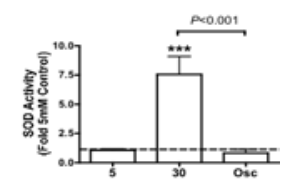

G.

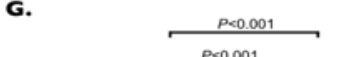

H.
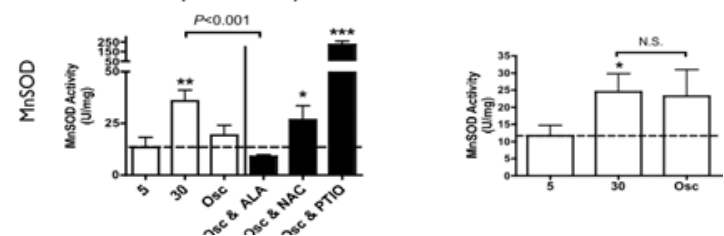

A.
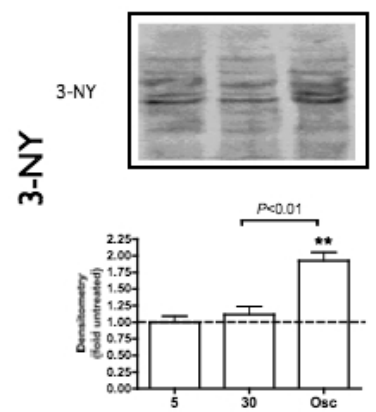

c.

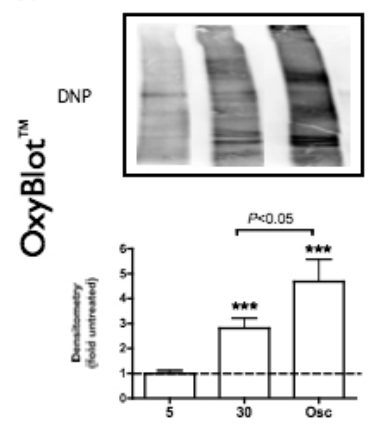

B.
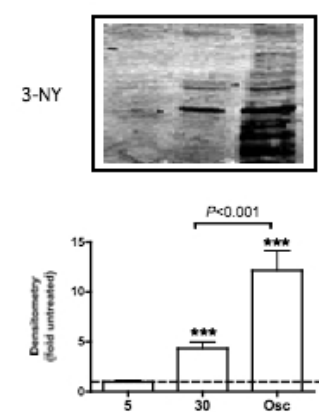

D.
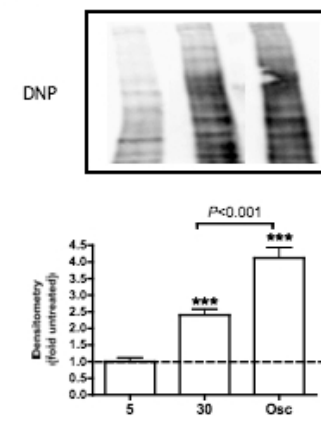

Fig. 2: $\quad$ 3-NT (panels A and B) and DNP-derivatized (OxyBlot ${ }^{\mathrm{TM}}$ ) (panels $\mathrm{C}$ and $\mathrm{D}$ ) protein expression in pericytes and ARPE-19 cells in response to chronic high continuous glucose and intermittent high glucose. Representative western blot for 3-NT (75 $\mu \mathrm{g}$ protein) and DNP (20 $\mu \mathrm{g}$ protein) shown above the densitometry of bands from western blots. From left to right, results are shown for cells exposed for 14 days to $5 \mathrm{mM}$ glucose, $30 \mathrm{mM}$ glucose, $5 \mathrm{mM}$ glucose oscillating daily with $30 \mathrm{mM}$ glucose. $n=4-6$ from 2-3 separate experiments. ${ }^{*} P<0.05$; ${ }^{* *} P<0.01,{ }^{* *} P<0.001$ using a one-way ANOVA with a Neuman-Keuls multiple comparisons post-test

Fig. 1: SOD protein expression and activity in pericytes and ARPE19 cells in response to chronic high continuous glucose and intermittent high glucose. Representative western blot for $\mathrm{Cu}, \mathrm{Zn}$ SOD and $\beta$-actin (panels A, B) $(50 \mu \mathrm{g}$ protein) or MnSOD and $\beta$-actin (panels C, D) $(20 \mu \mathrm{g}$ protein) are shown above graphs of total SOD (panels E, F) and MnSOD (panels $\mathrm{G}, \mathrm{H}$ ) enzyme activities. From left to right, results are shown for cells exposed for 14 days to $5 \mathrm{mM}$ glucose, $30 \mathrm{mM}$ glucose, $5 \mathrm{mM}$ glucose oscillating daily with $30 \mathrm{mM}$ glucose with or without $200 \mu \mathrm{M} \alpha$-lipoic acid (ALA) or $1 \mathrm{mM} \mathrm{N}$ acetylcysteine (NAC) given during the last 7 days. $n=8-15$ for each treatment condition with 3-4 separate experiments. Basal (5 mM glucose) levels for total SOD were 141.3 \pm 31.2 $\mathrm{U} / \mathrm{mg}$ for pericytes and $90.6 \pm 8.0 \mathrm{U} / \mathrm{mg}$ for ARPE- 19 cells. Basal ( $5 \mathrm{mM}$ glucose) levels for MnSOD were $47.9 \pm 5.7$ $\mathrm{U} / \mathrm{mg}$ for pericytes and $39.8 \pm 8.0 \mathrm{U} / \mathrm{mg}$ for ARPE-19 cells. ${ }^{*} P<0.05 ;{ }^{* *} P<0.01, * * P<0.001$ using a one-way ANOVA with a Neuman-Keuls multiple comparisons post-test

adduction has been shown to affect the function of a number of target proteins ${ }^{[27-29]}$, including $\mathrm{MnSOD}^{[28]}$. Levels of 3-NT were found to be increased in both

retinal pericytes and ARPE-19 cells in response to oscillating as compared to either normal or high continuous glucose (Fig. 2A and 2B).

Oscillating glucose results in increased oxidized protein levels in retinal cells: We next performed an OxyBlot $^{\mathrm{TM}}$ assay, which derivatizes oxidized protein carbonyl groups to a 2,4-dinitrophenylhydrazone (DNP) moiety, which can be then detected using anti-DNP antibodies and is a method to assess general oxidative damage to a protein. As with 3-NT, levels of DNPderivatized proteins were significantly increased in both retinal pericytes and ARPE-19 cells in response to oscillating glucose as compared to either chronic high continuous or normal glucose exposure (Fig. 2C and 2D). 

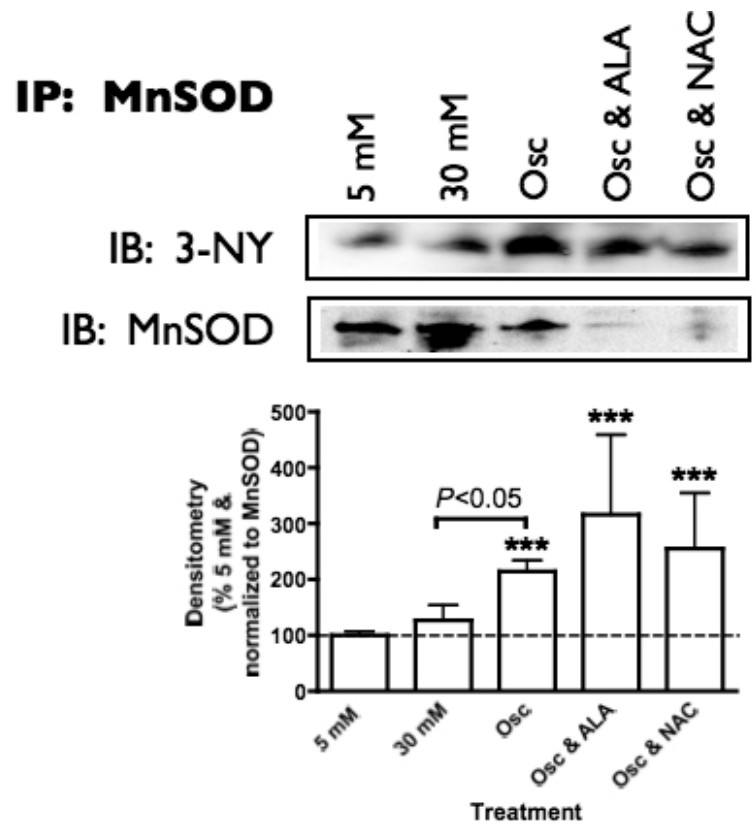

Fig. 3: Effect of oscillating glucose on nitrated MnSOD. Pericytes were exposed to chronic high continuous glucose and intermittent high glucose for 14 days with or without $200 \mu \mathrm{M}$ $\alpha$-lipoic acid (ALA) or $1 \mathrm{mM} \mathrm{N}$-acetylcysteine (NAC) given during the last 7 days. Whole cell lysates were coimmunoprecipitated against MnSOD and western blot against 3-NT (top panel), MnSOD (middle panel) completed as in methods. The densitometric analysis of 3-NT and MnSOD expression shown in the top panel was then graphed as a percentage of normoxic 3-NT/MnSOD expression (bottom panel). Data represent the mean $+/$ SEM from 2 independent experiments with an $\mathrm{n}=4-7$. $*=\mathrm{P}<0.05, * *=\mathrm{P}<0.01$ and $* * *$ $=\mathrm{P}<0.001$ using a one-way ANOVA with a Neuman-Keuls multiple comparisons post-test

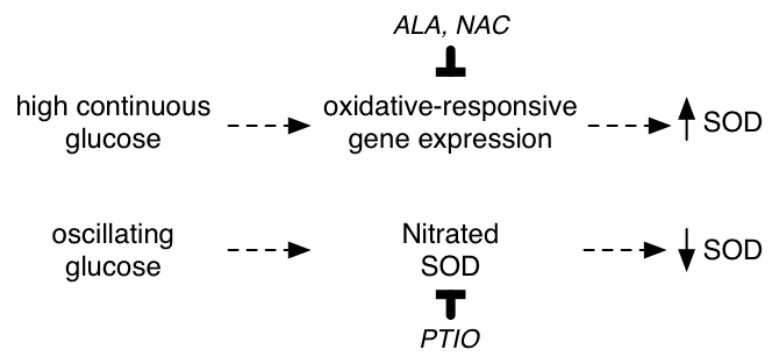

Fig. 4: Hypothesis diagram. In retinal cells in response to high continuous glucose, we hypothesize that a ROS-mediated induction of SOD gene expression predominates while in response to intermittent high glucose a RNS-mediated nitration (inactivation) of SOD predominates

Intermittent high glucose results in increased levels of nitrated MnSOD: To begin to explore the mechanistic basis of the decreased induction of SOD activity in response to oscillating as compared to continuous high glucose (Fig. 1E-G) and because nitration of the MnSOD protein has been shown to attenuate its activity ${ }^{[28]}$, we examined whether chronic exposure to oscillating glucose would affect MnSOD nitration. Using immunoprecipitation (IP) against MnSOD and a western blot against 3-NT (Fig. 3; top blot), it was found that exposure to high continuous glucose resulted in slightly more nitrated MnSOD than normal glucose and that exposure to oscillating glucose resulted in significantly increased levels of nitrated MnSOD as compared to either high continuous or normal glucose exposure. To confirm whether reactive species were contributing to the nitration, the general antioxidants $\alpha$-lipoic acid (ALA) ${ }^{[24]}$ or $\mathrm{N}$-acetylcysteine $(\mathrm{NAC})^{[25]}$ were added only to the last wk (out of two wk total) of oscillating glucose so as to not affect the baseline redox status of the cells. It was found that both of these antioxidants resulted in decreased levels of nitrated MnSOD (Fig. 3; top blot, rightmost lanes). These 3-NT blots were then reprobed with a MnSOD antibody raised in another species (Fig. 3; middle blots) and the densitometry of bands graphed as a ratio of 3NT:MnSOD (Fig. 3; bottom graph). It was found that oscillating glucose resulted in significant increases in 3NT/MnSOD ratios as compared to high continuous glucose. In addition, it was found that these 3NT/MnSOD ratios were the highest in cells given antioxidants in the last wk of oscillating glucose (Fig. 3; bottom graph, rightmost lanes), but that the absolute levels of MnSOD protein (Fig. 3; middle blot) and MnSOD activity (Fig. 1G) in response to these general antioxidants was much lower as compared with high or oscillating glucose exposure alone. Finally, to examine the effect of RNS on SOD activity in response to oscillating glucose, the nitric oxide/peroxynitrite scavenger 2-phenyl-4,4,5,5-tetramethylimidazoline-1oxyl-3-oxide (PTIO) was added to the last wk of oscillating glucose $\mathrm{e}^{[5]}$ and resulted in a significant induction of SOD activity (Fig. 1E and 1G).

\section{DISCUSSION}

In the present work, we demonstrate that the induction of total cellular superoxide dismutase (SOD) activity in isolated retinal pericytes is significantly attenuated in response to intermittent high glucose as compared to continuous high glucose. A similar effect is observed in an RPE cell line (ARPE-19). We further show that two markers of reactive species and levels of nitrated MnSOD are also increased in cells exposed to intermittent high (oscillating) glucose as compared to high continuous glucose.

As mentioned in the introduction, an excess of reactive oxygen and nitrogen species in a cell is a function of production on one hand and removal on the 
other. We have shown previously that intermittent high glucose in endothelial cells results in increased markers of reactive species even when compared with continuous high glucose $\mathrm{e}^{[5-9]}$. In this work we confirm in retinal pericytes and ARPE-19 cells that intermittent high glucose results in increased 3-NT and for the first time, that the levels of 3-NT adducted (nitrated) MnSOD increases in response to intermittent high as compared with high continuous glucose. However, we found that intermittent high glucose results in an attenuated SOD induction in isolated cells of a target organ for diabetes, the retina. These results, therefore, suggest that this unbalanced response of an antioxidant defense may account for the increased oxidative stress in oscillating glucose conditions.

There are two studies that suggest that SOD is not induced in the retinas of galactose-mediated hyperglycemic rats or in STZ-induced diabetic rats $^{[30,31]}$, which seem to go against our data in response to high continuous glucose. Possible explanations for this apparent discrepancy are: 1) the retina contains many cell types and in this work we examined only pericytes and RPE cells; and 2) the time of hyperglycemia exposure in the galactosemia model ( 2 months) or diabetic rats (11 months) was different than that in our studies ( $2 \mathrm{wk}$ ). Additionally, in the same study by Kowluru et al..$^{[23,30,31]}$, short-term high glucose (48-96 h) induced nitrosative stress in retinal cells in culture and MnSOD overexpression protected these cells from oxidative stress, while the effect of high glucose on SOD in these cells was not evaluated ${ }^{[31]}$. In contrast to the findings with SOD, neither high continuous glucose nor intermittent high glucose resulted in substantial induction of GPx or CAT activity in the retinal cells. Although we and others have shown that high glucose has been shown to induce GPx and CAT in many different cells and tissues ${ }^{[11,12,32-35]}$, there is most certainly a divergent and perhaps cell-specific regulation of these antioxidant enzymes. Our lack of induction with GPx and CAT also fit well with similar findings in the retina of hyperglycemic animals ${ }^{[30]}$. Taken together, these data build a picture of compromised reactive species removal in response to intermittent high glucose in retinal cells, which can explain why 3-NT and the OxyBlot ${ }^{\mathrm{TM}}$ products were found to be increased in response to intermittent high as compared to continuous high glucose.

A discrepancy between protein levels and enzyme activity was found in our experiments. This may be due to changes in protein activity subsequent to modification of the antioxidant enzymes by reactive species. For example, the MnSOD protein has been shown to be a target for inactivation by nitration ${ }^{[26]}$. The
IP of MnSOD with a subsequent 3-NT western blot demonstrates that pericytes exposed to oscillating versus high continuous glucose showed significantly increased nitration of MnSOD, which was reduced by the general antioxidants ALA and NAC. Further, a decrease in the induction of MnSOD protein, total SOD activity and MnSOD activity was observed when general (relatively weak) antioxidants, ALA in particular, was added to the last wk of oscillating glucose while the addition of the more specific RNS scavenger PTIO resulted in a significant increase in SOD activity (Fig. 1E/1G). This has led us to hypothesize that in response to continuous high glucose, excess ROS stimulate SOD expression via oxidative-responsive changes in gene expression ${ }^{[36]}$ whereas in response to intermittent high (oscillating) glucose, RNS produced result in significant increases in nitrated MnSOD leading to attenuated SOD induction $^{[28]}$ (Hypothesis Diagram - Fig. 4).

From a clinical point of view, these data may help to explain the emerging evidence that disease states associated with fluctuations in glucose, namely postprandial hyperglycemia ${ }^{[1]}$ and impaired glucose tolerance $(\mathrm{IGT})^{[2]}$, are related to an increased risk of developing retinopathy. Of note, the American Diabetes Association (ADA) has just established the new category of impaired fasting glucose (IFG) patients based on the evidence that $2 \mathrm{hr}$ values during an oral glucose tolerance were correlated with the risk of developing retinopathy ${ }^{[37]}$. Moreover, these data fit well with clinical findings showing attenuated induction of antioxidant activity in diabetic patients prone to complications ${ }^{[38-40]}$ and support the argument of a defective intracellular antioxidant response leading to increased susceptibility to diabetic complications.

\section{CONCLUSION}

The results demonstrate for the first time a link between intermittent high glucose and a decreased induction of an antioxidant response of SOD. The precise mechanism is still unclear, however this finding may help to explain, even in part, why intermittent high glucose results in more of an excess of oxidative stress as compared to continuous high glucose. A better understanding as to why this happens is clearly an important future question in the context of being able to prevent blindness from diabetic retinopathy.

\section{ACKNOWLEDGEMENTS}

This study was funded by an NIH/NCRR Center for Biomedical Research Excellence (COBRE) program project "Mentoring Vision Research in Oklahoma" (1P20RR017703-01) (M.A.I). 


\section{REFERENCES}

1. Ceriello, A., 2005. Postprandial hyperglycemia and diabetes complications: Is it time to treat? Diabetes, 54: 1-7.

2. Singleton, J.R., A.G. Smith, J.W. Russell and E.L. Feldman, 2003. Microvascular complications of impaired glucose tolerance. Diabetes, 52: 28672873.

3. Shichiri, M., H. Kishikawa, Y. Ohkubo and N. Wake, 2000. Long-term results of the Kumamoto Study on optimal diabetes control in type 2 diabetic patients. Diabetes Care, 23 (Suppl 2): B21-9.

4. Risso, A., F. Mercuri, L. Quagliaro, G. Damante and A Ceriello, 2001. Intermittent high glucose enhances apoptosis in human umbilical vein endothelial cells in culture. Am. J. Physiol. Endocrinol. Metab., 281: E924-30.

5. Quagliaro, L., L. Piconi, R. Assaloni, L. Martinelli, E. Motz and A Ceriello, 2003. Intermittent high glucose enhances apoptosis related to oxidative stress in human umbilical vein endothelial cells: the role of protein kinase $\mathrm{C}$ and $\mathrm{NAD}(\mathrm{P}) \mathrm{H}$-oxidase activation. Diabetes, 52: 2795-2804

6. Quagliaro, L., L. Piconi, R. Assaloni, R. Da Ros, A. Maier, G. Zuodar and A. Ceriello, 2005. Intermittent high glucose enhances ICAM-1, VCAM-1 and E-selectin expression in human umbilical vein endothelial cells in culture: the distinct role of protein kinase $\mathrm{C}$ and mitochondrial superoxide production. Atherosclerosis, 183: 259267.

7. Piconi, L., L. Quagliaro, R. Assaloni, R. Da Ros, A. Maier, G. Zuodar and A. Ceriello, 2006. Constant and intermittent high glucose enhances endothelial cell apoptosis through mitochondrial superoxide overproduction. Diabetes Metab. Res. Rev., 22: 198-203.

8. Takeuchi, A., D.C. Throckmorton, A.P. Brogden, N. Yoshizawa, H. Rasmussen and M. Kashgarian, 1995. Periodic high extracellular glucose enhances production of collagens III and IV by mesangial cells. Am. J. Physiol., 268(1 Pt 2): F13-9.

9. Jones, S.C., H.J. Saunders, W. Qi and C.A. Pollock, 1999. Intermittent high glucose enhances cell growth and collagen synthesis in cultured human tubulointerstitial cells. Diabetologia, 42:1113-1119.

10. Nishikawa, T., D. Edelstein, X.L. Du, S. Yamagishi, T. Matsumura, Y. Kaneda, M.A. Yorek, D. Beebe, P.J. Oates, H.P. Hammes, I. Giardino and M. Brownlee, 2000. Normalizing mitochondrial superoxide production blocks three pathways of hyperglycaemic damage. Nature, 404: 787-790.
11. Ceriello, A., P. dello Russo, P. Amstad and P. Cerutti, 1996. High glucose induces antioxidant enzymes in human endothelial cells in culture. Evidence linking hyperglycemia and oxidative stress. Diabetes, 45: 471-477.

12. Catherwood, M.A., L.A. Powell, P. Anderson, D. McMaster, P.C. Sharpe and E.R. Trimble, 2002. Glucose-induced oxidative stress in mesangial cells. Kidney Int., 61: 599-608.

13. Ceriello, A., N. Bortolotti, E. Motz, A. Crescentini, S. Lizzio, A. Russo, L. Tonutti and C. Taboga, 1998. Meal-generated oxidative stress in type 2 diabetic patients. Diabetes Care, 21: 1529-1533.

14. Ceriello, A., L. Quagliaro, B. Catone, R. Pascon, M. Piazzola, B. Bais, G. Marra, L. Tonutti, C. Taboga and E. Motz, 2002. Role of hyperglycemia in nitrotyrosine postprandial generation. Diabetes Care, 25: 1439-1443.

15. Sinclair, S.H., 2006. Diabetic retinopathy: The unmet needs for screening and a review of potential solutions. Expert. Rev. Med. Devices, 3: 301-313.

16. Podesta, F., G. Romeo, W.H. Liu, S. Krajewski, J.C. Reed, C. Gerhardinger and M. Lorenzi, 2000. Bax is increased in the retina of diabetic subjects and is associated with pericyte apoptosis in vivo and in vitro. Am. J. Pathol., 156: 1025-1032.

17. Li, W., X. Liu, M. Yanoff, S. Cohen and X. Ye, 1996. Cultured retinal capillary pericytes die by apoptosis after an abrupt fluctuation from high to low glucose levels: A comparative study with retinal capillary endothelial cells. Diabetologia, 39: 537-547.

18. Li, W., X. Liu, Z. He, M. Yanoff, B. Jian and X Ye, 1998. Expression of apoptosis regulatory genes by retinal pericytes after rapid glucose reduction. Invest. Ophthalmol. Vis. Sci., 39: 1535-1543.

19. Blair, N.P., M.O. Tso and J.T. Dodge, 1984. Pathologic studies of the blood--retinal barrier in the spontaneously diabetic $\mathrm{BB}$ rat. Invest. Ophthalmol. Vis. Sci., 25: 302-311.

20. Dircks, C., E.H. Williams and P.A. Campochiaro, 1987. High glucose concentrations inhibit protein synthesis in retinal pigment epithelium in vitro. Exp. Eye Res., 44: 951-958.

21. MacGregor, L.C. and F.M. Matschinsky, 1986. Experimental diabetes mellitus impairs the function of the retinal pigmented epithelium. Metabolism, 35(4 Suppl 1): 28-34.

22. King, A., E. Gottlieb, D.G. Brooks, M.P. Murphy and J.L. Dunaief, 2004. Mitochondria-derived reactive oxygen species mediate blue light-induced death of retinal pigment epithelial cells. Photochem. Photobiol., 79: 470-475. 
23. Kowluru, R.A., 2005. Diabetic retinopathy: mitochondrial dysfunction and retinal capillary cell death. Antioxid. Redox. Signal, 7: 1581-1587.

24. Smith, A.R., S.V. Shenvi, M. Widlansky, J.H. Suh and T.M. Hagen, 2004. Lipoic acid as a potential therapy for chronic diseases associated with oxidative stress. Curr. Med. Chem., 11:1135-1146.

25. Hattori, Y., S. Hattori, N. Sato and K. Kasai, 2000. High-glucose-induced nuclear factor kappaB activation in vascular smooth muscle cells. Cardiovasc. Res., 46: 188-197.

26. Pacher, P., I.G. Obrosova, J.G. Mabley and C. Szabo, 2005. Role of nitrosative stress and peroxynitrite in the pathogenesis of diabetic complications. Emerging new therapeutical strategies. Curr. Med Chem., 12: 267-275.

27. Zou, M., C. Martin and V. Ullrich, 1997. Tyrosine nitration as a mechanism of selective inactivation of prostacyclin synthase by peroxynitrite. Biol. Chem., 378: 707-713.

28. MacMillan-Crow, L.A. and J.A. Thompson, 1999. Tyrosine modifications and inactivation of active site manganese superoxide dismutase mutant (Y34F) by peroxynitrite. Arch. Biochem. Biophys., 366: $82-88$.

29. Daiber, A., S. Herold, C. Schoneich, D. Namgaladze, J.A. Peterson and V. Ullrich, 2000. Nitration and inactivation of cytochrome P450BM3 by peroxynitrite. Stopped-flow measurements prove ferryl intermediates. Eur. J. Biochem., 267: 6729-6739.

30. Kowluru, R.A., T.S. Kern and R.L. Engerman, 1997. Abnormalities of retinal metabolism in diabetes or experimental galactosemia. IV. Antioxidant defense system. Free Radic. Biol. Med., 22: 587-592.

31. Kowluru, R.A., L. Atasi and Y.S. Ho, 2006. Role of mitochondrial superoxide dismutase in the development of diabetic retinopathy. Invest. Ophthalmol. Vis. Sci., 47: 1594-1599.

32. Yokoyama, T., K. Yamane, A. Minamoto, H. Tsukamoto, H. Yamashita, S. Izumi, G. Hoppe, J.E. Sears and H.K. Mishima, 2006. High glucose concentration induces elevated expression of antioxidant and proteolytic enzymes in cultured human retinal pigment epithelial cells. Exp. Eye Res., 83: 602-609.
33. Weidig, P., D. McMaster and U. Bayraktutan, 2004. High glucose mediates pro-oxidant and antioxidant enzyme activities in coronary endothelial cells. Diabetes Obes. Metab., 6: 432441.

34. Sechi, L.A., A. Ceriello, C.A. Griffin, C. Catena, P. Amstad, M. Schambelan and E. Bartoli, 1997. Renal antioxidant enzyme mRNA levels are increased in rats with experimental diabetes mellitus. Diabetologia, 40: 23-29.

35. Zelko, I.N., T.J. Mariani and R.J. Folz, 2002. Superoxide dismutase multigene family: a comparison of the CuZn-SOD (SOD1), Mn-SOD (SOD2) and EC-SOD (SOD3) gene structures, evolution and expression. Free Radic. Biol. Med., 33: 337-349.

36. Wong, T.Y., E.L. Barr, R.J. Tapp, C.A. Harper, H.R. Taylor, P.Z. Zimmet and J.E. Shaw, 2005. Retinopathy in persons with impaired glucose metabolism: the Australian Diabetes Obesity and Lifestyle (AusDiab) study. Am. J. Ophthalmol., 140: 1157-1159.

37. Anonymous, 2006. Diagnosis and classification of diabetes mellitus. Diabetes Care, 29 (Suppl 1): S43-8.

38. Ceriello, A., A. Morocutti, F. Mercuri, L. Quagliaro, M. Moro, G. Damante and G.C. Viberti, 2000. Defective intracellular antioxidant enzyme production in type 1 diabetic patients with nephropathy. Diabetes, 49: 2170-2177.

39. Hodgkinson, A.D., T. Bartlett, P.J. Oates, B.A. Millward and A.G. Demaine, 2003. The response of antioxidant genes to hyperglycemia is abnormal in patients with type 1 diabetes and diabetic nephropathy. Diabetes, 52: 846-851.

40. Chiarelli, F., D. Di Marzio, F. Santilli, A. Mohn, A. Blasetti, F. Cipollone, A. Mezzetti and A. Verrotti, 2005. Effects of irbesartan on intracellular antioxidant enzyme expression and activity in adolescents and young adults with early diabetic angiopathy. Diabetes Care, 28: 1690-1697. 